\title{
A Diffusion Model for Preannounced Products
}

\author{
Delphine Manceau • Jehoshua Eliashberg • \\ Vithala R. Rao • Meng Su
}

Published online: 20 December 2013

(C) Springer Science+Business Media New York 2013

\begin{abstract}
Strategic preannouncement of a new product launch by a firm creates a pent-up demand (or consumers committed to purchase prior to launch) for the new product. The level of the pent-up demand depends, among other factors, on the timing and the reputation of the firm announcing the new product; it is critical in shaping up the diffusion process of the new product after launch. In this paper, we develop a two-phase diffusion model that describes both the impact of the announcement on consumers' purchase commitments and the diffusion process since launch starting with a strictly positive number of new product orders. We illustrate the empirical performance of the model with an old but classic dataset that captures both advance purchase orders as well as sales after launch for a new audio CD. We discuss how our model can guide a firm's decision on when to preannounce the introduction of its new product or technology, relative to the time of launch, so as to maximize the total benefit during the planning horizon.
\end{abstract}

Keywords Preannounced products · Credibility of firms . Diffusion and adoption processes

\section{Manceau}

ESCP Europe, Paris, France

e-mail: manceau@escpeurope.eu

\section{J. Eliashberg}

The Wharton School, University of Pennsylvania, Philadelphia, PA, USA

e-mail: eliashberg@wharton.upenn.edu

\section{R. Rao $(\bowtie)$}

Johnson Graduate School of Management, Cornell University, Ithaca, NY, USA

e-mail: vrr2@cornell.edu

\section{Su}

Guanghua School of Management, Peking University, Beijing, China e-mail: sumeng@gsm.pku.edu.cn

\section{Introduction}

The frequency of new product failure has been extremely high for several decades [1-5]. As product life cycles get shorter, rapid market penetration has become a major strategic advantage necessary to increase the profitability of new products [6-9]. Consequently, firms try to design strategies that enhance the likelihood of success by accelerating the diffusion process.

In this paper, we focus and analyze one key element of new products' launching strategy adopted by firms in various industries — preannouncements - and analyze its consequences on the diffusion of the new product. Many firms deliberately announce their new products before making them available to consumers [10]. For instance, Microsoft's X-Box has been announced 15 months before the expected release date and Sony's PlayStation II 12 months before being launched in Japan $[11,12]$. More recently, the very first iPhone has been announced 6 months before its launch [13] and WiiU, 5 months before being launched in the US [14]. In another industry, the next Star Wars movie, episode 7, has been announced 3 years in advance [15]. During the time period between the preannouncement date and the release (i.e., the product availability date), the firm may allow consumers to commit themselves to the new product by placing orders that are fulfilled later.

Preannouncements might be beneficial for several reasons related to either competitors or consumers [16-18]. An early announcement appears as a competitive signal that might preempt competition and deter entry [19-22]. It also creates a favorable marketing environment for the new product [23]. A preannouncement develops opinion leaders' support and favorable word-of-mouth [24]. Wind and Mahajan [25] regard this "marketing hype" as an efficient way to improve the chances of a successful launch. Kohli [26] considers that in rapidly changing technological environments, early 
announcements can play a critical role in the introduction of new products. Robertson [7] argues that they can accelerate the takeoff of a new product and reduce market penetration cycle times, that is, the amount of time it takes to reach maximum sales potential for the product. While investigating on the potential drawbacks of preannouncement strategy in terms of loss in brand trust when consumers face delays [27] or in terms of unwanted competitors' reactions [9, 22], recent research identified that this strategy offers main advantages for investors [19] and might positively influence shareholders value [9].

To our knowledge, no research to date has studied formally the diffusion of preannounced products and identified the extent to which diffusion might be affected by an early announcement. This paper focuses on the antecedents and consequences of early announcements on consumers rather than competitors and analyzes their impact on the diffusion process. We develop a two-phase diffusion model inspired to some degree by the Bass (1969) model [28].

The first phase of our model deals with the consumers' commitment process for the new product prior to launch. In this phase, we model the impact of the announcement on purchase commitments before the product is actually available in the market. We argue that the preannouncement fosters communication about the forthcoming product among the target population and induces some consumers to commit to purchase the product even though they know that they will have to wait until delivery begins. Our model of the prior-tolaunch commitment process accounts for pre-launch orders, when consumers can order the product before market introduction. At launch time, the demand for the product is strictly positive and corresponds to the commitment level resulting from the commitment process prior to launch. The level of commitment at launch time, as we argue in this paper, should be considered by management as a key milestone in the launching strategy.

In the second phase, we model the commitments made by consumers after the product launch. Because of the prelaunch commitments, the second-phase commitment process starts with a strictly positive level. This differs from most published diffusion models, in particular the numerous applications of the Bass (1969) model, where the cumulative number of adoptions (or commitment level) at launch is assumed to be equal to zero. In our model, we show how the early announcement and its resulting commitments at launch accelerate the diffusion process over time after the new product introduction. An early announcement thus appears as an efficient strategy to achieve faster market penetration.

The theoretical foundation of our model lies in diffusion theory. The diffusion of an innovation is a process by which an innovation "is communicated through certain channels over time among the members of a social system" [3, p.5]. Mahajan, Muller, and Bass [29] regard diffusion as a theory of communication focusing on communication channels. The preannouncement of a new product is a communication strategy related to a new product and is transmitted to and within the social system. The news, usually first released by the media, leads to the development of interpersonal communication. Diffusion theory takes into account media communication and word-of-mouth. Both communication channels are relevant to analyze the diffusion of information about a forthcoming product.

The main impetus underlying diffusion research in marketing is the one-phase Bass (1969) model in which the potential adopters of an innovation are influenced by word-of-mouth and media communication. The mathematical structure of the model is derived from a hazard function [30] corresponding to the conditional probability that an adoption will occur at time $t$ given that it has not occurred yet. If $f(t)$ is the density function of time to adoption and $F(t)$ is the cumulative fraction of adopters at $t$, the basic hazard function underlying the Bass model is $h(t)=\frac{f(t)}{1-F(t)}=p+q F(t)$. Parameter $q$ reflects the influence of those consumers who have already adopted the product (i.e., word-of-mouth communication from previous adopters), while $p$ captures the propensity to innovate that is independent from the number of adopters (i.e., external communication). Since 1969, many models, built upon this framework, have analyzed the impact of various marketing strategies with descriptive and normative purposes [31]. By contrast, we propose a two-phase model including the time period where the product is not available for delivery but its announcement generates a process where consumers make commitments for the new product. This approach has two key advantages: higher descriptive accuracy and the opportunity to investigate the managerial implications of product preannouncements.

The paper is organized as follows. In the next section, we describe the model and its underlying assumptions. The "Managerial Implications of the Model" section provides a discussion of the managerial implications of our model. In "Conclusions and Further Research" section, we conclude with suggestions for further research. In the appendix, we present an illustrative application with an old but classic dataset.

\section{The Model}

\subsection{A Two-Phase Model: Conceptual Framework}

We analyze the diffusion of preannounced products through a two-phase model. In the first phase, the product is announced but not available. Consumers slowly become aware of the existence of this "phantom product" and consider this alternative when they make their purchase decisions [32, 33]. Some consumers make a commitment to purchase it, knowing that 
they cannot get the product immediately because it is not available yet for delivery. The first phase reflects the commitment process for the new product before it is actually launched. It deals with the number of consumers who, between the announcement and the launch, get committed to purchase the product and wait for the delivery process to start at launch time.

In the second phase of the model, the product is available on the market. As soon as it is launched, and hence, becomes available, the firm delivers it to its committed consumers. The second-phase process thus starts with a strictly positive initial commitment level. This is a major difference from the typical applications of the Bass (1969) model and many of its extensions. In these applications, the cumulative number of adoptions is taken as zero at launch. In our model, the presence of the preannouncement and the formation of purchase commitments prior to launch lead to a positive cumulative pent-up demand level at launch time. Such a phenomenon was observed for the latest Apple's phones since "Apple reported that it sold 9 million iPhone 5c's and 5s's in the first 3 days it was available" [34]. Figure 1 shows the sequence of events as well as the situation we are interested in modeling. The product announcement occurs at time $t=T_{\mathrm{A}}$. Phase $1\left[T_{\mathrm{A}}, T_{\mathrm{L}}\right]$ shows the cumulative commitment process prior to launch, $N 1(t)$. Consumers become aware that a new product is forthcoming through media communication and some word-of-mouth. Some of them commit to purchase it. The product launch occurs at time $t=T_{\mathrm{L}}$ and then phase 2 begins. At launch time, $T_{\mathrm{L}}$, a total of $N 1\left(T_{\mathrm{L}}\right)$ consumers are committed to purchase the product. At this time, a new commitment process $N 2(t)$ starts, based on new parameters reflecting the fact that consumers do not have to wait for the delivery (i.e., different innovation propensity) and committed consumers now own the product (based on it a different interpersonal communication process evolves). The announcement-launch timing interval is referred to as $T_{\mathrm{L}}-T_{\mathrm{A}}$ in the paper.

\subsection{The First Phase of the Model—Assumptions and Modeling Approach}

The first phase of the model deals with the number of consumers committed to purchase the product before it is available on the market. When the firm registers orders for the forthcoming product before launch, those commitments correspond to pre-launch orders.

The preannouncement is first publicized in the media. It then generates word-of-mouth and buzz on the new product [24]. The information thus spreads among the population, builds interest for the new product, and leads some consumers to decide to purchase it [35]. Some consumers develop interest in getting the product as close to its introduction as possible [25]. As in the Bass model, people become aware of the existence of the new product through external and internal communication.

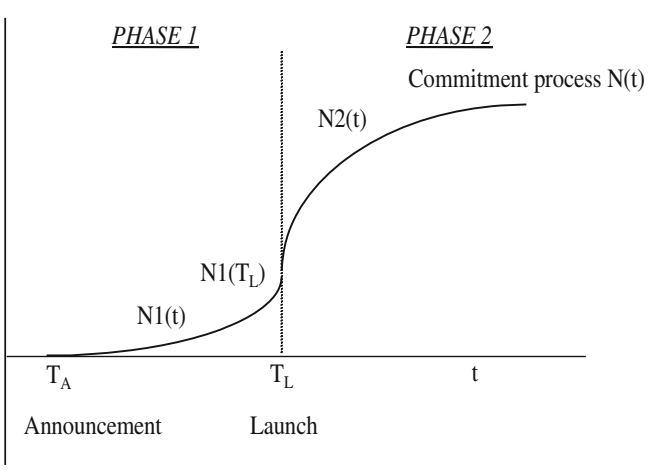

Fig. 1 Structure of the model

However, specific characteristics of preannouncements must be included in the model. Two key factors are taken explicitly into consideration in our modeling approach. First, the model addresses consumers deciding to adopt the product without being able to get it before launch time. Interpersonal communication thus only refers to verbal information from people already committed to buy the product and not to the imitation of actual adopters. Second, consumers know that the product is not yet available on the market, which might lead them to question the trustworthiness of the preannouncement. We thus add a credibility factor related to the characteristics of both the announcement and the firm.

We include these factors via a hazard function corresponding to the conditional probability that a purchase commitment occurs at time $t$ given that it has not occurred yet. We thus follow Cox and Oakes' [30] modeling approach by using a time-variant hazard function related to the time left before the product launch. The hazard function underlying the model for the commitment process prior to launch is of the form:

$h 1(t)=\frac{x 1(t)}{1-\mathrm{X} 1(t)}=\left[p_{1}+q_{1} X 1(t)\right]^{*} C\left(T_{\mathrm{L}}-t, r\right) \quad$ for $\quad T_{\mathrm{A}} \leq t \leq T_{\mathrm{L}}$

where $X 1(t)$ is the cumulative fraction of committed consumers at time $t$ between the announcement and the product launch and $x 1(t)=\frac{d X 1(t)}{d t} . C\left(T_{\mathrm{L}}-t, r\right)$ is the announcement credibility factor and it is formulated as a function of both the time before launch $\left(T_{\mathrm{L}}-t\right)$ and the firm's reputation $(r)$. Parameters $p_{1}$ and $q_{1}$ capture the innovation effect corresponding to external communication and the imitation effect among committed consumers, respectively.

\subsubsection{Interpersonal Communication}

In the Bass model and many of its extensions, the probability that an adoption will occur at time $t$ given that it has not occurred yet increases with the fraction of population that has already adopted. The imitation factor is related to 
interpersonal communication between adopters and potential adopters. In our model, only verbal communication contributes to imitation. Committed consumers talk about the forthcoming product and their decision to purchase it. Since the preannouncement generates word-of-mouth on the new product $[24,25]$, we expect some of this word-of-mouth to generate imitation between committed consumers and potential consumers who are not committed yet. Referring to Frenzen and Nakamoto's [36] conceptualization of word-of-mouth, we note that committed consumers face a low moral hazard when considering to transmit the information on the new product and on their own commitment because inducing other consumers to get committed is costless to them ${ }^{1}$. They thus are likely to transmit the information easily. Since committed consumers have decided to purchase the preannounced product, we expect them to spread positive information so that the imitation parameter $q_{1}$ is positive ${ }^{2}$. We thus assume that the conditional probability to commit to purchase the forthcoming product is related to the fraction of population that is already committed.

We employ a diffusion function akin to Bass [28]. However, we hypothesize that the imitation parameter might be smaller than in other diffusion models, which are based on observed sales, because imitation here is limited to the impact of verbal communication and not to the imitation of actual adoption. This is an empirical issue examined later in the paper. Moreover, one may also hypothesize that the coefficient of imitation will not differ significantly from zero: it might happen that committed consumers do not spread information about their purchase decision and that no real imitation process takes place before launch.

\subsubsection{Credibility Factor}

The credibility of an early announcement affects the decision of consumers with regard to the product $[27,37]$. Communications about a forthcoming product are not always believed. Consumers know that vaporware is a common practice in some industries and that many preannounced products are launched after a long delay. For instance, $\mathrm{Wu}$, Balasubramanian, and Mahajan [40] found that $70 \%$ of key informants in the computer hardware, software, and telecommunications industries

\footnotetext{
${ }^{1}$ Especially when they have already ordered the product and know for sure that they will be delivered before the consumers ordering it later on ${ }^{2}$ Some diffusion models have reported negative word-of-mouth effect for new products $[38,39]$. However, we do not believe this is likely to occur in this first phase of the model since committed consumers have not experienced the product yet. Their opinion is mostly based on the external information they have gathered on the new product, which has led them into committing to purchase it.
}

had encountered some delay when introducing a preannounced product and launched it several weeks after the announced date. Forty-seven percent of a sample of software products studied by Bayus, Jain, and Rao [21] has been launched with a delay over 3 months compared to their announced release date. Whether the company intends to announce a vaporware or originally intends to launch the product at the announced date but has experienced some delay in the new product development, the frequent preannouncement delays induce consumers to question the chances that the launch will actually occur at the launch date. Consumers also know that some preannounced products are never introduced on the market and that others are launched with very different features from the ones originally announced. Consumers thus might question the credibility of the information received about forthcoming products, whether it comes from the media or from people they know.

We model this phenomenon through a credibility factor that mediates the effect of communication on purchasing commitment. For the sake of simplicity, we consider the credibility of the media and of word-of-mouth to be similar. We focus on credibility factors related to the reputation of the announcing firm and to the timing left before the preannounced market introduction.

Robertson and Gatignon [41] argue that good reputation of suppliers speeds the diffusion of innovations because it enhances the relationship and confidence that exist between suppliers and potential adopters, and because a high reputation and credibility of the firm reduce uncertainty about the new product. In industries where preannouncements are common practice, consumers often form an opinion based on the firm's past behavior to evaluate the trustworthiness of their signals. Herbig, Milewicz, and Golden [42] have shown that the credibility of a signal highly depends on the reputation of the firm. Consequently, the higher the reputation of the firm, the more credible is the announcement.

A given announcement regarding the launching date is more credible as the launch date gets closer. Fewer events can happen between now and the expected release date that could put into question the launching of the product. The firm has almost finished both the product conception and the launch preparation. Consequently, credibility increases as the time period remaining to launch $\left(T_{L}-t\right)$ gets shorter. Putting the two factors together, we formulate the credibility factor in (1) as:

$C\left(T_{\mathrm{L}}-t, r\right)=e^{-\lambda_{r}\left(T_{\mathrm{L}}-t\right)}$

\footnotetext{
${ }^{3}$ Some may argue that the information spread by word-of-mouth is more trustworthy than the news published in the media. We do not make any such distinction here and consider both sources of communication to have the same level of credibility.
} 
where $\lambda_{r} \geq 0$ is the firm's reputation parameter and $0<C\left(T_{\mathrm{L}}-\right.$ $t, r) \leq 1$ as long as $T_{\mathrm{A}} \leq t \leq T_{\mathrm{L}}$. Note that $\lambda_{r}$ gets smaller when the reputation increases, i.e.,

$\frac{\mathrm{d} \lambda_{r}(r)}{\mathrm{d} r} \leq 0 \quad$ with $\quad \lambda_{r} \geq 0$

Because

$\frac{\mathrm{d} C\left(T_{\mathrm{L}}-t\right)}{\mathrm{d}\left(T_{\mathrm{L}}-t\right)}=-\lambda_{r} e^{-\lambda_{r}\left(T_{\mathrm{L}}-t\right)} \leq 0$,

the shorter the time left before launch, the more credible the announcement.

The multiplicative formulation in Eq. (2) corresponds to the fact that firms with higher reputation (smaller $\lambda_{r}$ ) can afford to preannounce earlier-larger $\left(T_{\mathrm{L}}-t\right)$-in order to generate the same credibility level $(C)$. As suggested above, in our model, reputation thus moderates the impact of timing. When the reputation is bad (low $r$ ), $\lambda_{r}$ is high and the credibility factor $C\left(T_{\mathrm{L}}-t, r\right)=e^{-\lambda_{r}\left(T_{\mathrm{L}}-t\right)}$ decreases rapidly with the time left before launch. For highly reputed firms, on the contrary, time before launch has lesser impact on the preannouncement credibility: people believe the announcement even if the product is to be launched much later. At launch time (that is, when the time left before launch tends towards zero), however, consumers consider the launching as extremely likely and the information spread about the product's features as highly trustworthy; the credibility parameter tends toward one whatever the reputation.

Note that the impact of the time left before market introduction can also be analyzed as a discount factor related to the motivation for consumers to get committed to purchase the product before it is introduced. Consumers are more inclined to commit to purchase a product likely to be available sooner than later. The closer the expected launch ${ }^{4}$, the higher is the motivation to make a purchase decision as well as the credibility of the announcement. Besides, since this $C$-factor has the effect of gradually increasing the base hazard rate as $t$ approaches $T_{\mathrm{L}}$, one may also interpret it as the impact of cumulative pre-launch marketing effort increasing the pool of consumers aware and interested in the product as the launch date gets closer. Many companies actually increase the pace of public relations, advertising, and web communication on preannounced products as the timing for launch approaches.

\footnotetext{
${ }^{4}$ We assume that the time of launch is known to the consumers for certain. Extensions of the model are possible when $T_{\mathrm{L}}$ is stochastic; but these do not add much insight to the process being modeled.
}

\subsubsection{Putting it All Together}

The model of the commitment process prior to launch is expressed as a multiplication of the two factors presented above, the communication spread about the forthcoming product and the credibility function $C$ from Eq. (2). The probability that purchase commitment occurs at time $t$ given that it has not occurred yet is thus given by:

$$
\begin{aligned}
h 1(t) & =\frac{x 1(t)}{1-X 1(t)}=\left[p_{1}+q_{1} X 1(t)\right]^{*} C\left(T_{\mathrm{L}}-t, r\right) \\
& =\left[p_{1}+q_{1} X 1(t)\right] \cdot e^{-\lambda r\left(T_{\mathrm{L}}-t\right)} \quad \text { for } T_{\mathrm{A}} \leq t \leq T_{\mathrm{L}}
\end{aligned}
$$

where $\lambda_{r} \geq 0$ captures the reputation in a way that $\frac{d \lambda_{r}}{d r} \leq 0$.

Note that at the best level of reputation $\left(\lambda_{r}=0\right)$, the credibility factor is equal to 1 and Eq. (5) corresponds to the standard Bass hazard function. The model thus allows the possibility that there is no credibility issue and that the consumers never question the fact that the product will be launched in the conditions that have been announced.

Since no consumer is committed to purchase the product at the time when the announcement occurs, i.e., $X 1\left(T_{\mathrm{A}}\right)=0$, the closed-form solution of the differential Eq. (5) is:

$$
X 1(t)=\frac{1-e^{-\frac{p_{1}+q_{1}}{\lambda_{r}}\left[e^{-\lambda_{r}\left(T_{\mathrm{L}}-t\right)}-e^{-\lambda_{r}\left(T_{\mathrm{L}}-T_{\mathrm{A}}\right)}\right]}}{1+\frac{q_{1}}{p_{1}} e^{-\frac{p_{1}+q_{1}}{\lambda_{r}}\left[e^{-\lambda_{r}\left(T_{\mathrm{L}}-t\right)}-e^{-\lambda_{r}\left(T_{\mathrm{L}}-T_{\mathrm{A}}\right)}\right]}} \text { for } T_{\mathrm{A}} \leq t \leq T_{\mathrm{L}}
$$

Equation (6) models the cumulative fraction of the market committed to purchase the new product at any time between the announcement and the launching. $X 1(t)$ is convex whenever ${ }^{5}$ :

$\lambda_{r} \geq p_{1}-q_{1}$

We expect such a condition to hold in many cases. Most previous empirical applications of the Bass model reported an innovation parameter $p$ lower than the imitation parameter $q$ [43]. Since parameter $\lambda_{r}$ is positive, the condition expressed in Eq. (7) holds whenever $q_{1} \geq p_{1}$. When the innovation parameter is higher than the imitation parameter, which is entirely possible here if the imitation process prior-to-launch is low, only a firm with a good reputation (i.e., a low $\lambda_{r}$ ) would not fulfill the condition expressed in Eq. (7). The function $X 1(t)$ could then be concave.

\footnotetext{
${ }^{5}$ The proof of $X 1(t)$ convexity under condition (7) is available from the authors upon request.
} 


\subsubsection{The Commitment Level at Launch}

The function $X 1(t)$ tells what fraction of the market is committed to purchase the product at the launch date $t=T_{\mathrm{L}}$, that is, when the product deliveries begin. It is given by:

$$
X 1\left(T_{\mathrm{L}}\right)=\frac{1-e^{-\frac{p_{1}+q_{1}}{\lambda_{r}}\left[1-e^{-\lambda_{r}\left(T_{\mathrm{L}}-T_{\mathrm{A}}\right)}\right]}}{1+\frac{q_{1}}{p_{1}} e^{-\frac{p_{1}+q_{1}}{\lambda_{r}}}\left[1-e^{-\lambda_{r}\left(T_{\mathrm{L}}-T_{\mathrm{A}}\right)}\right]}
$$

At launch time, the second phase of the model thus starts with initial condition, $X 1\left(T_{\mathrm{L}}\right)>0$. That is, $M_{1} X 1\left(T_{\mathrm{L}}\right)$ consumers are already committed to purchase the product from the very first week, where $M_{1}$ is the pre-launch market potential for the new product, that is the maximum number of consumers that might get committed to purchase before the product is actually released. We now describe the second phase of the model.

\subsection{The Second Phase of the Model}

When product's delivery begins at launch time, $T_{\mathrm{L}}$, a classical diffusion process starts with the specificity of an initial positive number of cumulative adopters $N_{1}\left(T_{\mathrm{L}}\right)=M_{1} X 1\left(T_{\mathrm{L}}\right)>0$. We now model the number of consumers purchasing the new product after its market introduction $X 2(t)$. We use the Bass (1969) diffusion model to account for the commitment process post-launch, with a hazard function given by:

$h 2(t)=\frac{x 2(t)}{1-X 2(t)}=p_{2}+q_{2} X 2(t), \quad t \geq T_{\mathrm{L}}$

where $X 2(t)$ is the cumulative fraction of committed consumers at time $t$ after the product launch, $x 2(t)=\frac{d X 2(t)}{d t}, p_{2}$ is the innovation parameter corresponding to external communication post-launch, and $q_{2}$ is the imitation parameter post-launch related to word-of-mouth spread by consumers committed to purchase the product. Note that we explicitly consider that both the post-launch innovation and imitation parameters might not be equal to their levels prior to launch. Since the attractiveness of the new product and the nature of the comments made by committed consumers can change after the product release, there is no reason to believe that $p_{2}$ will be equal to $p_{1}$ and $q_{2}$ will be equal to $q_{1}$. We also consider it possible that the market potential for the product might be somewhat different after launch since some consumers might be interested in the product when it has been released, but reluctant at getting committed to purchase it as long as they have not seen it. We thus include in the model two different market potential sizes before and after launch $\left(M_{1}\right.$ and $\left.M_{2}\right)$.
The difference between Eq. (9) and the Bass model is related to the fact that $X 2\left(T_{\mathrm{L}}\right)$ is not equal to zero but, instead, strictly positive. Because the preannouncement has started the commitment process prior to launch, $M_{2} X 2\left(T_{\mathrm{L}}\right)=M_{1} X 1\left(T_{\mathrm{L}}\right)$ consumers are committed to purchase the product at launch. This initial condition and the substitution of $X 1\left(T_{\mathrm{L}}\right)$ from Eq. (8) leads to the following closed-form solution for the cumulative commitments post-launch:

$$
X 2(t)=\frac{1-p_{2} \frac{1-\frac{M_{1} X 1\left(T_{\mathrm{L}}\right)}{M_{2}}}{p_{2}+q_{2} \frac{M_{1} X 1\left(T_{\mathrm{L}}\right)}{M_{2}}} e^{-\left(p_{2}+q_{2}\right)\left(t-T_{\mathrm{L}}\right)}}{1+q_{2} \frac{1-\frac{M_{1} X 1\left(T_{\mathrm{L}}\right)}{M_{2}}}{p_{2}+q_{2} \frac{M_{1} X 1\left(T_{\mathrm{L}}\right)}{M_{2}}} e^{-\left(p_{2}+q_{2}\right)\left(t-T_{\mathrm{L}}\right)}}, t \geq T_{\mathrm{L}}
$$

To sum up, the general structure of the two-phase model is based on the two equations: Eq. (6) describes the consumer commitment process in phase one, prior to launch, and gives the commitment level at launch; Eq. (10) draws the diffusion process in phase two, after the product market introduction. Seven parameters need to be estimated for our model; these are the sizes of the market potential, $M_{1}$ and $M_{2}$ before and after launch, two innovation parameters $p_{1}$ and $p_{2}$ before and after the product launch, two imitation parameters $q_{1}$ and $q_{2}$ before and after launch, and the reputation parameter $\lambda_{r}$. Our twophase structure accounts for the fact that the diffusion process may deeply change after the launching of the product and may be based on new innovation and imitation parameters. Krishnan, Bass, and Kumar [43] also developed a two-phase diffusion model to account for such changes in the diffusion of a product after a major event by changing some parameters before and after the event. However, the event they focus on is the late entry of a new brand, while we analyze a complete different issue.

\subsection{Comparison to Two Benchmark Models}

Our model has two specific characteristics: it is a two-phase model and it includes a credibility factor related to the reputation of the firm. These two characteristics account for the situations where our model is relevant as compared to the standard Bass model starting either at launch or at the announcement of the new product.

Our two-phase model can be useful when the diffusion process changes at launch. If the diffusion process does not really start before launch, then a standard Bass model starting at launch seems easier to implement since it includes fewer parameters than our model. If the diffusion process starts 
before launch but does not really change when the product is released (or in other words, if the pre-launch orders and postlaunch sales follow a smooth inverted U-shaped curve), there exists only one process for the two phases and the proposed model has no advantage over a one-phase model. On the contrary, if one observes a discontinuity between the prelaunch orders and post-launch sales, one may conjecture that there are two processes - one for pre-launch and one for postlaunch - and our model is quite relevant. This can occur when there is a significant jump in sales at launch or when the diffusion process accelerates once the product is released. It might also sometimes happen that there are two distinct diffusion processes with two peaks, one before and one after launch. In such cases, our model should be more relevant than the standard Bass model based on one process.

The second characteristic of our model is to include a credibility factor related to the firm's reputation. As we noted earlier, if the reputation is excellent and $\lambda_{r}=0$, then the pre-launch model is the same as the Bass model starting when the product is announced and the proposed model has no advantage. Our model thus seems particularly relevant for preannouncements whose credibility may be questioned by customers.

In order to assess empirically the situations where our model is a significant contribution as compared to existing models, we compare its performance against two benchmarks. The first benchmark is the standard one-phase Bass (1969) model applied from time of announcement onwards, with a zero initial condition at announcement time. This model thus corresponds to the following equation:

$$
F(t)=M \frac{1-e^{-(p+q)\left(t-T_{\mathrm{A}}\right)}}{1+\frac{q}{p} e^{-(p+q)\left(t-T_{\mathrm{A}}\right)}} \quad, t \geq T_{\mathrm{A}}
$$

where $F(t)$ refers to cumulative consumer commitments (i.e., orders) at time $t$.

Our second benchmark is a two-phase diffusion model a la Bass (1969) with two phases separated at time of launch. The pre-launch phase starts at the time of preannouncement as given in Eq. (11) and post-launch phase starts at time of product launch with a zero initial condition at launch time $F\left(T_{\mathrm{L}}\right)=0$. (This contrasts with our proposed model, which specifies a strictly positive initial condition at launch time which is linked to the prelaunch phase.) The second phase of the second benchmark thus corresponds to the following equation:

$$
F(t)=M \frac{1-e^{-(p+q)\left(t-T_{\mathrm{L}}\right)}}{1+\frac{q}{p} e^{-(p+q)\left(t-T_{\mathrm{L}}\right)}} \quad \text { for } t \geq T_{\mathrm{L}} \text { and } F\left(T_{\mathrm{L}}\right)=0
$$

Our model captures situations where a product has been preannounced, and for which consumers made, periodically, purchasing commitments before and after the launching. In order to test it empirically, we need an appropriate data set for a product that has been ordered before (as well as after) its market introduction. With such data, our model and the benchmark models can be estimated with nonlinear least square estimation techniques [53]. We describe an illustrative application of the model with one appropriate dataset in the Appendix. This illustrative application shows that our model fares better than benchmark models in terms of fit and holdout prediction.

\section{Managerial Implications of the Model}

The model has several managerial implications related to announcement strategies designed by firms for their new products. We first discuss implications concerning phase one of the timing of product announcement and its consequences on the commitment level at launch. Next, we analyze the implications on the second phase of the model, related to the post-launch commitment process.

3.1 The Impact of the Timing Between the Announcement and the Launch on the Commitment Level at Launch

\subsubsection{When Should a Firm Preannounce the Launch of its New Product?}

Firms preannouncing their new products choose very different timing strategies, from a few weeks to several years before market introduction [21, 45, 46]. As Lilly and Walters [47] note, even though the announcement timing can significantly affect a new product's success, the marketing and economics literature provides few insights and guidelines on this component of a launching strategy. Kohli [26] identifies several variables affecting the announcement timing chosen by companies for their new products, but he does not provide normative guidelines.

Our model can be used to analyze the impact of the announcement timing (i.e., $T_{\mathrm{L}}-T_{\mathrm{A}}$ ) on the commitment level of the new product at launch and also to study how the timing affects the entire diffusion process. Equations (6) and (8) describe the evolution during the first phase of the model, and the commitment level at launch. From Eq. (8), it is straightforward to show that:

$$
\frac{\mathrm{d} X 1\left(T_{\mathrm{L}}\right)}{\mathrm{d}\left(T_{\mathrm{L}}-T_{\mathrm{A}}\right)}=\frac{\left(p_{1}+q_{1}\right)^{2} e^{-\lambda_{r}\left(T_{\mathrm{L}}-T_{\mathrm{A}}\right)} e^{\frac{p_{1}+q_{1}}{\lambda_{r}}\left(e^{-\lambda_{r}\left(T_{\mathrm{L}}-T_{\mathrm{A}}\right)}-1\right)}}{p_{1}\left[1+\frac{q_{1}}{p_{1}} e^{\frac{p_{1}+q_{1}}{\lambda_{r}}\left(e^{-\lambda_{r}\left(T_{\mathrm{L}}-T_{\mathrm{A}}\right)}-1\right)^{2}}\right]}>0
$$


The commitment level for the preannounced product at launch increases monotonically with respect to the time between the announcement and the launch. Hence, the earlier the announcement, the higher will be the number of committed consumers when the product becomes available. However, we know from Eq. (8) that the commitment level at launch $X 1\left(T_{\mathrm{L}}\right)$ never goes beyond an asymptote corresponding to

$\overline{X 1}=\lim _{T_{\mathrm{A}} \rightarrow-\infty} X 1\left(T_{\mathrm{L}}\right)=\frac{1-e^{-\frac{p_{1}+q_{1}}{\lambda_{r}}}}{1+\frac{q_{1}}{p_{1}} e^{-\frac{p_{1}+q_{1}}{\lambda_{r}}}}$

A preannouncement thus cannot enable a firm to reach an initial fraction of consumers beyond this limit, which is strictly inferior to 1 . When the launch date is fixed, announcing the product earlier increases the number of committed consumers at launch but the benefit of an early preannouncement marginally diminishes. Note also that the better the firm's reputation (that is, the lower the parameter $\lambda_{r}$ ), the higher is $\overline{X 1}$ since the derivative $\frac{d \overline{X 1}}{d \lambda_{r}}=\frac{-\left(p_{1}+q_{1}\right)^{2} e^{-\frac{p_{1}+q_{1}}{\lambda_{r}}}}{p_{1} \lambda_{r}^{2}\left[1+\frac{q_{1}}{p_{1}} e^{-\frac{p_{1}+q_{1}}{\lambda_{r}}}\right]^{2}}$ is always negative. Thus, firms with better reputation can reach a higher fraction of the market potential through a preannouncement strategy than firms with low reputations.

\subsubsection{What Announcement Timing Should the Firm Choose so as to Reach a Given Commitment Fraction Level of the Market Potential?}

The expression for $\overline{X 1}$ in Eq. (14) can be considered as an important managerial milestone. If the launch date has already been decided (i.e., fixed $T_{\mathrm{L}}$ ), a firm can design its announcement strategy by selecting date $T_{\mathrm{A}}$ so that the time between the announcement and the launching $\left(T_{\mathrm{L}}-T_{\mathrm{A}}\right)$ enables it to reach a certain level of consumers' commitments at launch, knowing that this level is below the maximum fraction that can be reached, $\overline{X 1}$. If the firm aims at some fraction, say, $\alpha \overline{X 1}$, of potential consumers to be committed to purchase the product when it becomes available (with $0<\alpha<1$ ), then the firm can choose accordingly its announcement timing $T_{\mathrm{A}}=T_{\alpha}$ so that $X 1\left(T_{\mathrm{L}}\right)=\alpha \overline{X 1}$. That is:

$T_{\alpha}=T_{\mathrm{L}}+\frac{1}{\lambda_{r}} \ln \left[1-\frac{\lambda_{r}}{p_{1}+q_{1}} \ln \frac{1+\frac{q_{1}}{p_{1}} \alpha \overline{X 1}}{1-\alpha \overline{X 1}}\right]$ for $0<\alpha<1$

In practice, the firm can estimate the values of the parameters $p_{1}, q_{1}$, and $\lambda_{r}$ from its previously announced products and then employ Eq. (15) in order to reach a certain level of the market at launch. Of course, the choice of $\alpha$ should also be based on the firm's capability to meet the purchasing commitments made by its consumers at launch and thus depend on the firm's production capacity.

\subsubsection{How Does the Firms' Reputation Influence its Announcement Timing?}

Equation (15) also enables one to analyze the impact of the firm's reputation on the announcement timing adapted to reach a certain fraction of the market. It can be shown that $\frac{d\left(T_{\mathrm{L}}-T_{\alpha}\right)\left(\lambda_{r}\right)}{d \lambda_{r}} \geq 0{ }^{6}$. Consequently, the better the firms' reputation (the lower the $\lambda_{r}$ ), the shorter is the timing to choose between the announcement and the launch $T_{\mathrm{L}}-T_{\alpha}$ so as to reach a given fraction $\alpha \overline{X 1}$ of the market. Firms with a better reputation can thus choose a smaller $T_{\mathrm{L}}-T_{\alpha}$, that is, announce their product later (higher $T_{\alpha}$ ), to reach the same commitment level at launch (see [17]).

3.2 The Impact of the Announcement Timing on the Overall Diffusion

We have shown that the longer the timing between the announcement and the launch, the higher is the commitment level for the new product at launch time, even though this commitment level has a maximum limit which depends on the levels of the diffusion parameters as well as on the reputation of the firm. We now discuss the impact of the commitment level at launch on the post-launch diffusion process.

Since:

$$
\begin{aligned}
\frac{\partial X 2(t)}{\partial X 1\left(T_{\mathrm{L}}\right)}= & \frac{\left(p_{2}+q_{2}\right)^{2} e^{-\left(p_{2}+q_{2}\right)\left(t-T_{\mathrm{L}}\right)}}{\left[\left(p_{2}+q_{2} X 1\left(T_{\mathrm{L}}\right)\right)+q_{2}\left(1-X 1\left(T_{\mathrm{L}}\right)\right) e^{-\left(p_{2}+q_{2}\right)\left(t-T_{\mathrm{L}}\right)}\right]^{2}}>0 \\
& \text { for any } t \geq T_{\mathrm{L}}
\end{aligned}
$$

The presence of a high level of committed consumers at launch time increases the dynamics of the commitment process for the new product at any time after the product launch. Consequently, an early announcement will speed up the commitment process for the new product throughout the entire time horizon of interest. The higher the initial fraction of the market, $X 1\left(T_{\mathrm{L}}\right)$, that is committed to purchase the product at

\footnotetext{
${ }^{6}$ The proof for this proposition is available from the authors upon request.
} 
launch, due to the preannouncement, the higher the cumulative commitment level of the consumers at any time after launch.

This implication is related to word-of-mouth communication spread by committed consumers. The higher the number of people committed to purchase the product at any time after launch, the more intense is the diffusion of information and the higher is the number of cumulative commitments. The impact of the initial fraction of committed consumers thus remains through the whole diffusion process. This result supports formally the idea that an early announcement can accelerate diffusion [7].

However, note that the nature and the characteristics of the announcement strategy can influence the way the market reacts to the product when it becomes available. The level of the parameters of the commitment process post launch (i.e., $p_{2}$ and $q_{2}$ ) might be affected by the way the product has been announced as well as by the announcement timing. If the consumers feel they are disappointed with the product when it is actually introduced, or if they have been waiting for it too long, the innovation and imitation parameters might be smaller than if the announcement has been dealt with success $[9,27]$.

Some managerial implications of this model are summed up in Table 1 using different scenarios of decisions related to a preannouncement strategy. One of the main examples that follow these guidelines is the case of iPhone launches. Capitalizing of its good reputation, Apple implemented a preannouncement strategy for several versions of its mobile phone, based on external communication and imitation effect that led to intense word-of-mouth communication and increased the number of consumers committed at launch. Clearly, Acer, HTC, or Nokia have to adopt different preannouncement strategies for their new smartphones in order to take into account their different reputation as compared to Apple.

Besides the phone industry, the managerial implications we identify apply to several industries such as cars, video game consoles, B2B equipment, IT systems ...-all the industries with a strong commitment level from the client and a high level of word-of-mouth and imitation when making a purchase decision.

\section{Conclusions and Further Research}

\subsection{Summary}

In this paper, we have developed a two-phase new diffusion model to account for the commitment process of a preannounced new product. As described in the Appendix, this model was applied to an old but classic CDNOW dataset and outperformed the two benchmark models on fit and predictive criteria. We derived from the model some managerial implications on the timing of product announcements and their consequences on both the commitment level at launch and the post-launch commitment process.

Table 1 Scenarios of managerial implications

\begin{tabular}{|c|c|c|c|}
\hline & & Scenarios & Managerial implications \\
\hline \multirow[t]{3}{*}{ Pre-launch } & 1. & $\begin{array}{l}\text { Company seeks to identify when it should preannounce its } \\
\text { new product to reach a certain number of committed } \\
\text { consumers at launch. }\end{array}$ & $\begin{array}{l}\text { Provided that the targeted level of committed consumers is } \\
\text { reachable (based on Eq. 14), the timing can be chosen thanks } \\
\text { to the provided model (Eq. 15) given the level of reputation, } \\
\text { external communication level, and imitation effect. }\end{array}$ \\
\hline & 2. & $\begin{array}{l}\text { Company with good reputation seeks to identify to what } \\
\text { extent its reputation will influence consumers' } \\
\text { commitment in case of product preannouncement. }\end{array}$ & $\begin{array}{l}\text { The better the firm's reputation, the higher the consumers' } \\
\text { commitment level to be reached through a preannouncement } \\
\text { strategy. }\end{array}$ \\
\hline & 3. & $\begin{array}{l}\text { Company seeks to identify to what extent its reputation } \\
\text { may influence its announcement timing. }\end{array}$ & $\begin{array}{l}\text { The better the firm's reputation, the shorter is the timing to } \\
\text { choose between the announcement and the launch. }\end{array}$ \\
\hline \multirow[t]{3}{*}{ Post-launch } & 4. & $\begin{array}{l}\text { Company is willing to identify to what extent a high number } \\
\text { of committed consumers at launch time will influence } \\
\text { the level of committed consumers after launch. }\end{array}$ & $\begin{array}{l}\text { The higher the number of consumers committed to purchase the } \\
\text { product at launch due to preannouncement, the higher the } \\
\text { cumulative commitment level of the consumers at any time } \\
\text { after the launch. }\end{array}$ \\
\hline & 5. & $\begin{array}{l}\text { Company is willing to identify to what extent word of } \\
\text { mouth communication will influence consumers } \\
\text { commitment after launch. }\end{array}$ & $\begin{array}{l}\text { The higher the number of consumers committed to purchase the } \\
\text { product at any time after launch, the more intense the diffusion } \\
\text { of information, the higher the number of cumulative } \\
\text { commitments. }\end{array}$ \\
\hline & 6. & $\begin{array}{l}\text { Company is willing to know which announcement } \\
\text { strategy may influence market reaction at launch date. }\end{array}$ & $\begin{array}{l}\text { Announcement timing and nature communication are two main } \\
\text { dimensions that affect preannouncement strategy success, } \\
\text { especially external communication level and imitation affect } \\
\text { among consumers. }\end{array}$ \\
\hline
\end{tabular}




\subsection{Future Research Directions}

A first area of future research based on our model is to relate the parameters of the diffusion process post-launch to those of the pre-launch period. This relationship will depend upon the characteristics of the product, the market, and the announcement. It will be very useful to apply our model empirically to other situations in order to develop a repertoire of data, which will assist in building relationships between the pre-launch and post-launch parameters. A meta-analysis can be performed on such accumulated information on parameters for the purposes of conjecturing appropriate values for an announced product in the future.

A second area of future research would be to investigate the question of announcement timing and to relate it to the production capacity of the firm. Once a firm has decided to preannounce its new product, a strategic question of interest is when to announce the product relative to the launching time $\left(T_{\mathrm{L}}-T_{\mathrm{A}}\right.$ in our model)? Such a decision impacts on the pentup demand for the product at and after launch. Our model has enabled to investigate the impact of the announcement timing on the demand during the whole diffusion process. However, an increase in the commitment level should be considered in conjunction with the firm's capability to deliver the product to its committed consumers in a timely manner. Because of supply constraints, the new product manufacturer might not be able to deliver immediately all the committed consumers at launch time and afterwards. Supply constraints often occur for new durable products, like cars or telephones when introduced in Germany [48, 49]. Often, this production constraint creates a gap between commitments and deliveries that may last for a long period of time. In the case of a preannounced product, the commitment process prior to launch, leading to a positive commitment level at launch and to higher commitment levels during the whole post-launch process, might increase the chances for the existence of such a gap and make manufacturers unable to deliver the product to committed consumers before a long delay.

This issue could be addressed by making a distinction between deliveries and commitments after launch and by adding to our model a second post-launch process related to the delivery process. Jain, Mahajan, and Muller [50] have developed a diffusion model considering the impact of supply restrictions in which not every consumers who requests the product receives it immediately. They thus make a distinction between two dynamic processes, one for the delivered adopters of the product and another for the waiting applicants (i.e., committed consumers who placed orders and are waiting for the product delivery). However, in terms of time periods, their model is a single-phase one since the demand and supply processes start simultaneously with an initial number of zero at launch time. Our model could be extended through a twophase/three-process model with a second phase post-launch including both a demand process corresponding to the commitment process we have modeled in this paper and a supply process corresponding to the delivery process. It would allow us to study different levels of gaps between consumer commitments and product deliveries after the product is released.

The analysis of optimal announcement dates given the launch date would be of great interest through such a model. An earlier announcement would then have two consequences. One is to increase the pent-up demand for commitments at and after launch, and the other is the firm's inability to deliver the product to all of its committed consumers after the launch in a timely manner because of supply constraints. The first of this is a gain in net margin due to the deliveries and the second is a loss due to the opportunity cost of not satisfying consumers who ordered the new product. The objective, then, could be, for instance, to optimize the discounted net values of these two terms in order to reach a decision concerning the best time of announcement relative to launch time. This normative aspect of the model will be an interesting area for future research.

Finally, an announcement of new products by a firm is usually targeted at its consumers as well as its competitors. In this paper, we have focused on the diffusion process that pertains to consumers. However, the firm's competitive posture in terms of competitive equity building and of first-mover predisposition also influences the firm's propensity to preannounce [17]. Moreover, when a firm announces a product, there is often a reaction by its competitors $[16,22,51]$. Competitors' reactions are likely to increase the size of the market potential, $M$ of our model, as well as affect the diffusion parameters. A productive area for future research will be to develop a comprehensive model that explicitly takes into account competitors' reactions in addition to those of consumers' responses; see Su and Rao [46] so as Ofek and Turut [22] for some progress on this topic.

Acknowledgments The authors wish to acknowledge Wendy W. Moe and Peter S. Fader for sharing their data from CDNOW. Research support by the Sol C. Snider Entrepreneurial Research Center and Johnson School of Cornell University is also gratefully acknowledged. The authors are also grateful to Aurélie Hemonnet-Goujot, PhD student at ESCP Europe, for her help.

\section{Appendix: An Illustrative Application}

The music industry offers an appropriate setting to illustrate our model's performance empirically. Audio CDs, while losing popularity to various music streaming services these days, at the time, were often announced in advance and allowed consumers to order them in advance of their formal release date. Moe and Fader [52] provide several examples of such 
CD products. Moreover, a new CD can be considered as a short-term monopoly because the artist and the theme make it unique to the consumers, a situation explicitly modeled in this paper. Further, we need a sufficient number of data points before launch to estimate the first phase of the model.

We have identified an appropriate case in the Moe and Fader data set which has adequate pre-launch and postlaunch sales data points, needed to test our model. This is the CD called "Higher Ground" by Barbara Streisand. Its weekly sales are shown in Fig. 2. It was released on November 11, 1997. The order for this CD started 5 weeks before the release date. Data provide 38 data points after the release of the CD. We use weekly data on pre- and post-launch orders to estimate our model.

\section{Model Estimation}

We estimate the first phase of the model using five weekly prelaunch orders. The parameters of the equation describing the cumulative number of consumers' commitments prior to launch $N 1(t)=M_{1} X 1(t)$ with $X 1(t)$ from Eq. (6) were estimated using the nonlinear least squares procedure [53]. In applying this method of estimation, we encounter a problem in estimating the market size due to a large jump of $366 \%$ in the commitments (from 18 to 66 ) in the period prior to product launch. We solve this problem by adopting the mirror method which assumes the adoption process is symmetric with respect to time around the peak time [29, 44]; in our case, this means that the first phase diffusion reaches the peak at time of launch. The shape of diffusion curve from time $T_{\mathrm{L}}$ to $2 T_{\mathrm{L}}$ is the mirror image of the shape of diffusion curve from the announcement, 0 , to launch $T_{\mathrm{L}}$. The estimated parameters are the following: $\widehat{p}_{1}=0.0513$ (s.e. $\left.=0.1845\right), \widehat{q}_{1}=1.673$ (s.e. $\left.=2.2571\right)$, $\widehat{\lambda}_{r}=0.1151$ (s.e. $\left.=0.3006\right)$, and $\widehat{M}_{1}=160.3$ (s.e. $\left.=9.4658\right)$. We believe that the estimates of the model parameters are not significant ${ }^{7}$ due to the small number of observations. A strictly positive estimate for parameter $\lambda_{r}$ shows that the announcement is not highly credible in the pre-launch period. The MAPE for the estimation with five data points equals $24.79 \%$. The estimated parameters lead to an estimated cumulative commitment level at launch $\widehat{N} 1\left(T_{\mathrm{L}}\right)=103.72$, which is $10.58 \%$ below the actual level of $N 1\left(T_{\mathrm{L}}\right)=116$.

We then estimate the parameters of the second phase of the model using the nonlinear estimation method using the first 24 values after launch and imposing the condition on the cumulative number of commitments post-launch $N 2(t)=$ $M_{2} X 2(T)$ with $X 2(t)$ taken from Eq. (10), with the initial condition $N 2\left(T_{\mathrm{L}}\right)=\widehat{N} 1\left(T_{\mathrm{L}}\right)$ resulting from the estimation

\footnotetext{
${ }^{7}$ Nevertheless, the fit of our model for pre-launch phase is better than that of the Bass model as we show in the next section.
}

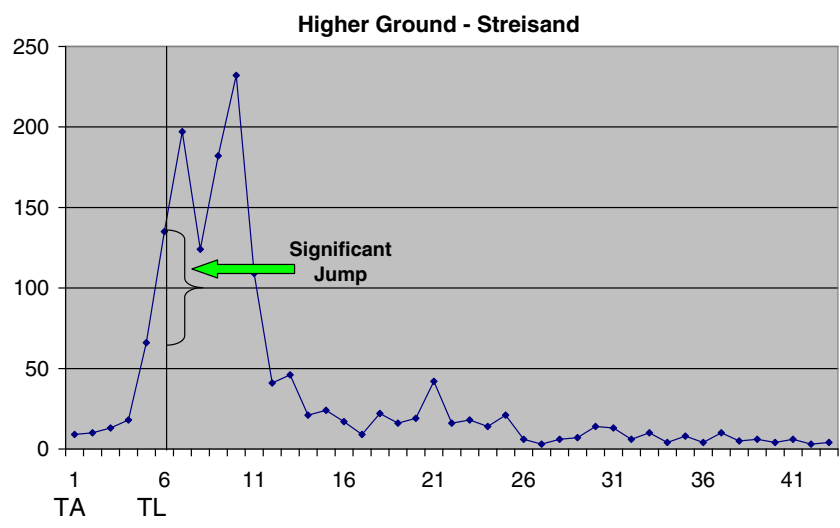

Fig. 2 Weekly sales of online CD - "Higher Ground"

of the first stage of the model. With the estimates from the first phase model, the cumulative fraction of committed consumers at the beginning of second phase is $\frac{M_{1} X 1\left(T_{\mathrm{L}}\right)}{M_{2}}=\frac{103.72}{M_{2}}$. The estimated parameters are $\widehat{p}_{2}=0.1451$ (s.e. $=0.0261$ ), $\widehat{q}_{2}=0.1184$ (s.e. $=0.078$ ), and $\widehat{M}_{2}=1403.3 \quad$ (s.e. $\left.=24.0828\right)$. Parameters $M_{2}$ and $p_{2}$ are significant. The MAPE equals $7.84 \%$. We then use these parameter estimates to do predictive testing on a holdout sample of 14 data points and obtain a MAPE of $6.78 \%$. The results of the two phases taken together provide some validity for our model both in terms of pre-launch and post-launch commitments.

\section{Models Comparison}

We estimate two benchmark models, the standard single phase Bass model (model 1) and the Bass model with different parameters in phase 1 and 2 (model 2 ), to compare against our proposed model 3 with non-zero initial condition in phase 2. Compared to model 1 and 2, our proposed model provides a better fit to the in-sample data and a better out-of-sample prediction (with the least MAPE, MAD, and AIC), as shown in Table 2. Note that both model 2 and model 3 significantly outperform model 1, indicating that the two-phase model is more appropriate in this situation where the diffusion process changes dramatically at the time of launch. Model 3 slightly improves over model 2, reducing the in-sample MAPE from 8.72 to $7.84 \%$ and MAD from 34.38 to 33.67 .

A commonly observed disadvantage of one-phase Bass model is the inaccurate estimate at time when market situation changes significantly (e.g., the launch of new product). For CD "Higher Ground", the sales during the period immediately after launch jumped by $105 \%$ compared to the commitments in the period immediately prior to launch (from 66 to 135). A two-phase Bass (model 2) can be used to improve the model fit and predictability. Nevertheless, model 3 that recognizes the link between pre-launch and post-launch phases outperforms model 2 ; this is probably due to the large sales jump 
Table 2 Models comparison

\begin{tabular}{cllll}
\hline Model description & Benchmark 1 & Benchmark 2 & $\begin{array}{l}\text { Proposed } \\
\text { model 3 } \\
\text { Two-phase/non- } \\
\text { zero initial } \\
\text { condition in } \\
\text { phase 2 }\end{array}$ \\
\hline Bn-sample fit & MAPE & 16.20 & 8.72 & $\begin{array}{l}\text { Two-phase } \\
\text { Bass model }\end{array}$ \\
& MAD & 47.20 & 34.38 & 33.67 \\
& AIC & 238.12 & 228.60 & 229.74 \\
Out-of-sample & MAPE & 9.71 & 6.84 & 6.78 \\
prediction & MAD & 146.49 & 103.28 & 102.41 \\
& AIC & 296.10 & 276.65 & 276.09 \\
\hline
\end{tabular}

Akaike's information criterion $(\mathrm{AIC}=n * \ln (\mathrm{MSE})+2 k)$ is also used to measure the model fit. The number of parameters is 3 for model 1,6 for model 2, and 7 for model 3

after launch. For example, model 3 reduces the MAPE of the first two periods after launch by $7 \%$ from model 1 and by $3 \%$ from model 2.

\section{References}

1. Booz, Allen, Hamilton Inc (1982) New product management for the 1980s. Booz, Allen and Hamilton, New York

2. Hauser J, Tellis G, Griffin A (2006) Research on innovation: a review and agenda for marketing science. Mark Sci 25(6):687-717

3. Rogers E (1983) Diffusion of innovations, 3rd edn. The Free Press, New York

4. Crawford M, Di Benedetto A (2011) New products management, 10th edn. McGraw-Hill, New York

5. Trott P (2011) Innovation management and new product development, 5th edn. Prentice Hall, London

6. Von Braun C (1990) The acceleration trap. Sloan Manag Rev 32: 401-421, Fall

7. Robertson T (1993) How to reduce market penetration cycle times. Sloan Manag Rev 35:87-96, Fall

8. Loch CH, Huberman BA (1999) A punctuated-equilibrium model of technology diffusion. Manag Sci 45(2):160-177

9. Sorescu A, Shankar V, Kushwaha T (2007) New product preannouncements and shareholder value: don't make promises you can't keep. J Mark Res 44(3):468-489

10. Porter M (1980) Competitive strategy. The Free Press, New York

11. The Economist (1999) Science and technology: smooth operator. March 6: 73-74

12. Time (2000) Game Wars. 155, 11 (March 20): 44-45

13. Yoffie DB, Kim R (2010) Apple Inc. in 2010. President and Fellows of Harvard College

14. Wall Street Journal (2012) Nintendo Puts Hope on New Wii at E3 Show. June 4

15. Forbes (2012) Lucas gives up Star Wars to Disney: Episode VII to be released in 2015. October 30

16. Robertson T, Eliashberg J, Rymon T (1995) Competitive new product signals and incumbent reactions. J Mark 59(3):1-15

17. Calantone R, Schatzel K (2000) Strategic foretelling: communication-based antecedents of a firm's propensity to preannounce. J Marketing 64(1):17-30
18. Su M, Rao VR (2010) New product preannouncement as a signaling strategy: an audience-specific review and analysis. J Prod Innovat Manag 27(5):658-672

19. Smiley R (1988) Empirical evidence on strategic entry deterrence. Int J Ind Organ 6(2):167-180

20. Heil O, Robertson T (1991) Competitive marketing signals: a research agenda. Strateg Manag J 12(6):403-418

21. Bayus B, Jain S, Rao A (2001) Truth or consequences: an analysis of vaporware and new product announcements. J Mark Res 38(1):3-13

22. Ofek E, Turut Ö (2013) Vaporware, Suddenware, and Trueware: new product preannouncements under market uncertainty. Market Sci 32(2):342-355

23. Schatzel K, Calantone R (2006) Creating market anticipation: an exploratory examination of the effect of preannouncement behavior on a new product's launch. J Acad Market Sci 34(3):357-366

24. Eliashberg J, Robertson T (1988) New product preannouncing behavior: a market signaling study. J Marketing Res 25(3):282-292

25. Wind Y, Mahajan V (1987) Marketing hype: a new perspective for new product research and introduction. J Prod Innovat Manag 4(1): 43-49

26. Kohli C (1999) Signaling new product introductions: a framework explaining the timing of preannouncement. J Bus Res 46(1):45-56

27. Herm S (2013) When things go wrong, don't rely on committed consumers: effects of delayed product launches on brand trust. J Prod Innovat Manag 30(1):70-81

28. Bass F (1969) A new product growth model for consumer durables. Manag Sci 18(5):215-227

29. Mahajan V, Muller E, Bass F et al (1993) New-product diffusion models. In: Handbooks in operations research and management science, marketing, vol 5. Elsevier Science, North Holland, pp 349-408

30. Cox DR, Oakes D (1984) Analysis of survival data, monographs on statistics and applied probability. Chapman Hall, New York

31. Mahajan V, Muller E, Wind J (2000) New-product diffusion models. Kluwer, Dordrecht

32. Farquhar P, Pratkanis A (1992) A brief history of research on phantom alternatives: evidence for seven empirical generalizations about phantoms. Basic Appl Psychol 13(1):103-122

33. Farquhar P, Pratkanis A (1993) Decision structuring with phantom alternatives. Manag Sci 39(10):1214-1226

34. Forbes (2013) Iphone 5c channel fill helped Apple to report nine million units sold. September 23

35. Le Nagard-Assayag E, Manceau D (2001) Modeling the impact of product preannouncements in the context of indirect network externalities. Int J Res Mark 18(3):203-219

36. Frenzen J, Nakamoto K (1993) Structure, cooperation and the flow of market information. J Consum Res 20(3):360-375

37. Brockhoff K, Rao VR (1993) Toward a demand forecasting model for preannounced new technological products. J Eng Technol Manag 10(3):211-228

38. Mahajan V, Muller E, Kerin RA (1984) Introduction strategy for new products with positive and negative word-of-mouth. Manag Sci 30(12):1389-140

39. Bayus BL, Gupta S (1992) An empirical analysis of consumer durable replacement intentions. Int J Res Market 9:257-267

40. Wu Y, Balasubramanian S, Mahajan V (2004) When is a preannounced new product likely to be delayed? J Mark 68(2): 101-113

41. Robertson T, Gatignon H (1986) Competitive effects of technology diffusion. J Marketing 50(3):1-12

42. Herbig P, Milewicz J, Golden J (1994) A model of reputation building and destruction. J Bus Res 31(1):23-31

43. Krishnan T, Bass F, Kumar V (2000) Impact of late entrant on the diffusion of a new product/service. J Mark Res 37(2):269-278

44. Mahajan V, Muller E, Srivastava RK (1990) Using innovation diffusion models to develop adopter categories. J Mark Res 27(1):37-50 
45. Biemans W, Setz H (1995) Managing new product announcements in the Dutch telecommunications industry. In: Bruce M, Biemans W (eds) Product development: meeting the challenge of the designmarketing interface. Wiley, New York, pp. 207-209

46. Su M, Rao VR (2011) Timing decisions of new preannouncement and launch with competition. Int J Prod Econ 129(1):51-64

47. Lilly B, Walters R (1997) Toward a model of new product announcement timing. J Prod Innovat Manag 14(1):4-20

48. Simon H, Sebastian K (1987) Diffusion and advertising: the German telephone campaign. Manag Sci 33(4):471-466
49. Urban G, Hauser J, Roberts J (1990) Prelaunch forecasting of new automobiles. Manag Sci 36(4):401-421

50. Jain DC, Mahajan V, Muller E (1991) Innovation diffusion in the presence of supply restrictions. Market Sci 10(1):83-90

51. Lilly B, Walters R (2000) An exploratory examination of retaliatory preannouncing. J Mark Theory Pract 8(4):1-9

52. Moe W, Fader P (2002) Using advance purchase orders to forecast new product sales. Market Sci 21(3):347-364

53. Srinivasan V, Mason CH (1986) Nonlinear least squares estimation of new product diffusion models. Market Sci 5(2):169-178 